\title{
TINJAUAN ATAS DESAIN SAMPUL MUKA \\ BUKU ANAK-ANAK REVOLUSI \\ KARYA BUDIMAN SUDJATMIKO
}

\author{
Danu Widhyatmoko \\ Visual Communication Design, School of Design, BINUS University \\ Jln. K.H. Syahdan No. 9, Palmerah, Jakarta Barat 11480 \\ danu@binus.edu
}

\begin{abstract}
The cover design is the face of the whole picture of the publication works, which not only serves as a media promotion but also as a medium of identification. This paper consists of a review of the cover design of a book of Anak-anak Revolusi by Budiman Sudjatmiko by using visual communication design approach. Then the choice will also be discussed in other visual approach that can be applied. Research method used in this paper is literature study, continued with reflective data analysis. By the end of the paper, a more comprehensive picture related object being reviewed. The book of Anak-anak Revolusi by Budiman Sudjatmiko has an excellent script and has an appropriate methaporic book cover. However, at the time of the visualization of the book cover is executed, there are many shortcomings that should have been optimized so that the book of Anak-anak Revolusi could be presented entirely and completely in many aspects.
\end{abstract}

Keywords: Anak-anak Revolusi, cover design, Budiman Sudjatmiko

\begin{abstract}
ABSTRAK
Desain sampul muka merupakan gambaran utuh dari karya publikasi, yang bukan saja berfungsi sebagai media promosi namun juga sebagai media identifikasi. Tulisan ini berisi tinjauan atas sampul muka buku Anak-anak Revolusi karya Budiman Sudjatmiko dengan menggunakan pendekatan desain komunikasi visual. Lalu juga akan dibahas pilihan pendekatan visual lain yang dapat diterapkan. Metode penelitian yang digunakan dalam penulisan ini adalah studi literatur yang dilanjutkan dengan analisa data reflektif. Hingga pada akhir tulisan bisa didapatkan gambaran yang lebih jelas terkait objek yang ditinjau. Buku Anak-anak Revolusi karya Budiman Sudjatmiko memiliki isi naskah yang hebat, memiliki pilihan metafora untuk sampul muka buku yang tepat. Walau demikian saat eksekusi visual masih ditemui kekurangan di sana-sini yang semestinya dapat dioptimalkan agar buku Anak-anak Revolusi dapat hadir lebih utuh, lengkap di segala aspek.
\end{abstract}

Kata kunci: Anak-anak Revolusi, desain sampul muka, Budiman Sudjatmiko 


\section{PENDAHULUAN}

Anak-anak Revolusi adalah autobiografi Budiman Sudjatmiko, aktivis oposisi orde baru yang kini menjabat sebagai anggota DPR. Autobiografi ini ditulis dalam format novel, mencatat perjalanan panjang sebuah mimpi dan harapan yang terus dijaga dan diperjuangkan. Selayaknya sebuah karya yang utuh, tiap elemen yang hadir dalam karya akan saling kait-mengait dan menguatkan. Begitu pun dengan desain sampul muka yang terdapat di buku ini. Desain sampul buku tersebut telah menjadi bagian utuh dari karya, seperti halnya pilihan jenis huruf yang digunakan di isi buku, jenis tata letak yang dipilih, finishing cetak dan elemen-elemen lainnya.

Tujuan penulisan ini adalah untuk melakukan tinjauan atas sampul muka buku Anak-anak Revolusi dilihat dari keilmuan desain komunikasi visual. Penulisan ini disusun menggunakan studi literatur dan analisa reflektif, guna menghasilkan gambaran yang utuh atas tinjauan desain yang dilakukan.

\section{METODE}

Penulisan ini disusun menggunakan pendekatan studi literatur untuk mendapatkan data-data pendukung serta mencari kerangka teori guna menguatkan hasil penulisan. Kemudian setelah data didapatkan maka akan dilakuakan analisa data refletif. Analisa Reflektif adalah metode analisa data yang berpedoman pada cara berfikir reflektif, yakni kombinasi yang kuat antara berfikir deduktif dan induktif atau dengan mendialogkan data teoritik dan data empirik secara bolak balik kritis (Stain, 2002).

Dengan metode analisa reflektif, penulis akan mencari makna yang terkandung dari hasil pengumpulan data yang telah dilakukan, untuk diperbandingkan antara literatur yang ada dengan keadaan ataupun fenomena yang tertangkap. Sehingga dapat diperoleh kesimpulan data yang rasional dan ilmiah.

\section{HASIL DAN PEMBAHASAN}

Buku Anak-anak Revolusi ini berukuran 14 x 21 cm dengan tebal 494 halaman. Hadir dengan dominasi latar berwarna putih dengan fokus yang diletakkan pada objek setangkai mawar merah yang tak lagi utuh, sekian kelopaknya telah terlepas, tercecer, lengkap dengan tangkai yang telah patah. Lalu masih dalam objek yang sama, dengan pendekatan closure (Lidwell; Holden; Butler, 2010), tervisualkan jejak sepatu lars yang tertinggal. Jejak sepatu lars tersebut terlihat jelas telah menginjak sebagian dari setangkai mawar merah. Finishing cetak sampul muka buku tersebut berjenis soft cover dengan finishing cetak berupa laminating doff. Pada tulisan judul buku dan nama penulis dilakukan finishing cetak berupa embossed dan spot UV Varnish. Judul buku dan nama penulis tersebut terpampang pada bagian bawah, menggunakan jenis huruf (typeface) Trajan (atau mungkin juga jenis huruf yang sejenis). Sedang di pojok kanan atas tercantum logo penerbit yakni Gramedia Pustaka Utama. Sebagai penyeimbang di bagian sisi kiri atas diletakkan splash dalam bentuk lingkaran oval sederhana berwarna merah bertuliskan "Buku 1". 


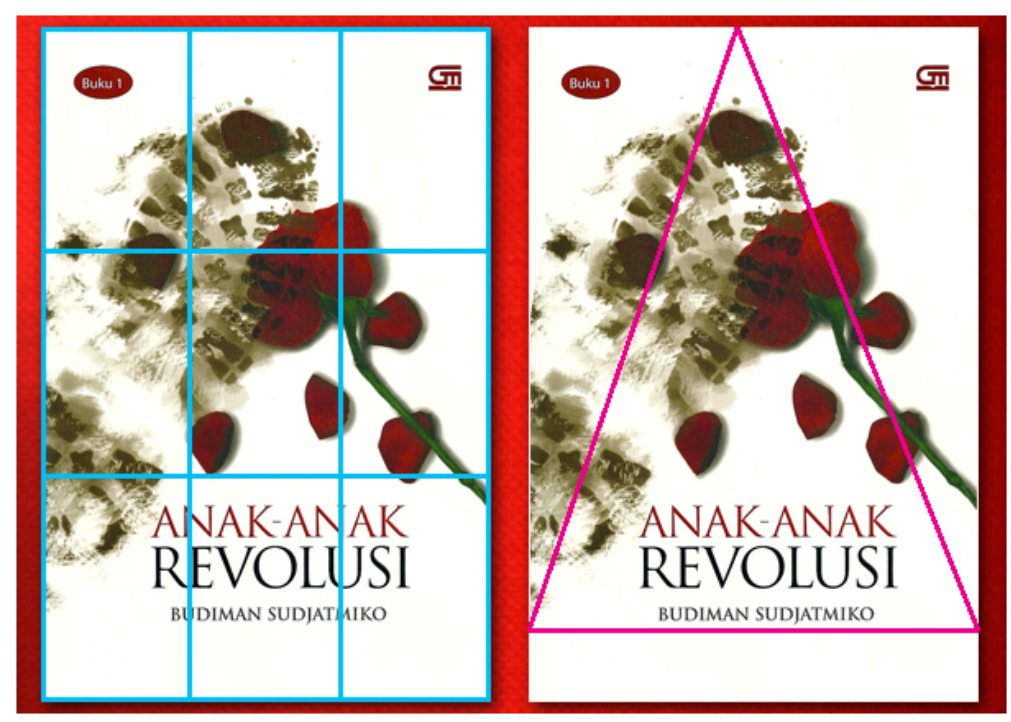

Gambar 1 Tata letak dan komposisi

Seperti yang tercantum dalam info penerbitan, sampul muka ini didesain oleh Andhika Pradana. Desain tata letak (layout) terasa berupaya mengimplementasikan rule of third (Lidwell; Holden; Butler: 2010), walau relatif tidak ketat dalam penerapannya, namun hal tersebut menjadi wajar karena berusaha membagi beban visual antara bidang kiri dan kanan yang condong lebih berat di area kiri. Area kiri yang lebih berat diberikan porsi ruang yang lebih lebar dibanding area sebelah kanan. Tata letak yang disajikan juga terlihat jelas berusaha membangun komposisi dalam bingkai segitiga, dengan objek yang berada di dalam garis semu sisi segitiga yang sama panjang maupun tidak (sisi dasar).

Menilik kata pengantar yang dituliskan, sepertinya ide, konsep dan hasil tampilan yang tersaji telah memenuhi harapan serta keinginan Budiman. Bahkan Budiman memberikan apresiasi tampilan sampul muka dengan mengkaitkan karya Costa Gavras, Missing. Missing adalah sebuah film yang bercerita tentang penculikan dan pembunuhan dengan adegan yang mengerikan dan penuh kekerasan. Film itu sendiri meraih penghargaan di ajang Oscar untuk kategori Best Screenplay Adaptation dan mendapatkan Palme d'Or di Cannes Film Festival.

Merujuk kepada Basic Figures of Speech, maka tampilan pada sampul muka buku Anak-anak Revolusi memilih untuk melakukan pendekatan metafora (Lupton, 2011). Pendekatan metafora itu sendiri berarti melakukan perbandingan secara langsung dengan menggunakan perbandingan objek yang analogis. Jejak sepatu lars merupakan metafora dari kekuasan yang represif. Kekuasaan yang berjalan dengan pola menekan, mengekang, menahan, juga menindas. Sedang mawar merah adalah bentuk metafora dari keindahan impian, romantisme, rasa cinta atas harapan, serta rasa hormat terhadap keinginan.

Sosok Budiman Sudjatmiko tidak dapat dilepaskan dengan aktivitas perlawanan terhadap orde baru. Peristiwa Kudatuli (akronim dari Kerusuhan Dua Puluh Tujuh Juli) 1996 tak bisa dipisahkan dari sosok Budiman. Peristiwa tersebut berlangsung dalam bentuk pengambilalihan secara paksa kantor DPP Partai Demokrasi Indonesia (PDI) di Jl. Diponegoro yang saat itu dikuasai oleh pendukung Megawati Sukarnoputri. Pengambilalihan tersebut dilakukan oleh massa pendukung Soerjadi (Ketua Umum versi Kongres PDI di Medan) serta dibantu oleh aparat dari kepolisian dan TNI. Terdapat mata rantai yang hilang dalam peristiwa tersebut, karena yang lebih banyak diketahui adalah rilis pemerintah orde baru, mereka merilis sebuah cerita dengan menempatkan sosok Budiman dengan 
Partai Rakyat Demokratik yang dipimpinnya sebagai dalang dari kerusuhan tersebut. Pertanyaan besar masih mengemuka, mencari mata rantai kejadian yang sesungguhnya terjadi, dari sisi pelaku utama, yakni sosok Budiman sendiri. Cerita yang berkembang hanyalah bentuk cerita mulut ke mulut, berbicara tentang aparat kekuasaan yang bergerak masif mencari para pelaku, sambil melakukan penculikan serta penyiksaan.

Namun belum pernah ada dokumen resmi yang secara gamblang dan runut menceritakan secara detail apa yang sesungguhnya terjadi. Para pembaca memiliki ekspektasi besar untuk mengetahui detail peristiwa tersebut. Ekspektasi itulah yang berusaha divisualkan dalam desain sampul muka buku Anak-anak Revolusi. Pemilihan metafora sebagai sebuah jembatan (bahasa) visual dengan objek mawar merah, jejak sepatu lars adalah pilihan yang tepat. Secara utuh dapat menangkap keseluruhan pesan yang menaungi isi buku tersebut. "Book covers work best when they combine simple yet powerful elements together in a unified whole that tells, at a glance, what the reader can expect from the book." (Friedlander, 2012).

\section{Kritik atas Visual Sampul Muka Buku Anak-anak Revolusi}

Narasi ini tidak akan membahas pilihan metafora serta elemen-elemen visual di dalamnya karena pilihan tersebut telah tepat pada fungsinya. Namun, terdapat beberapa hal yang masih dapat dieksplorasi serta dioptimalkan terkait elemen-elemen visual tersebut, terkait hal tersebut maka dapat dibagi menjadi tiga bahasan utama yaitu Tipografi, Eksekusi Visual dan Gaya Visual

\section{Tipografi}

Trajan adalah jenis huruf yang dipilih untuk menuliskan judul buku dan nama penulis buku Anak-anak Revolusi. Trajan dalam tipografi masuk dalam kategori jenis huruf old style serif, yang berarti jenis huruf dengan kait bergaya klasik, dirancang oleh Carol Twombly untuk Adobe pada tahun 1989 (Meggs \& Purvis 2006). Seluruh huruf yang dimiliki Trajan adalah uppercase (kerap diterjemahkan menjadi "huruf besar" dalam bahasa Indonesia) atau disebut juga berjenis huruf allcapitals (Lupton, 2004). Bila membutuhkan versi lowercase-nya biasanya akan memilih menggunakan Trajan Pro yang berjenis small-capitals, jenis huruf ini mempertahankan bentuk uppercase yang dimiliki Trajan.

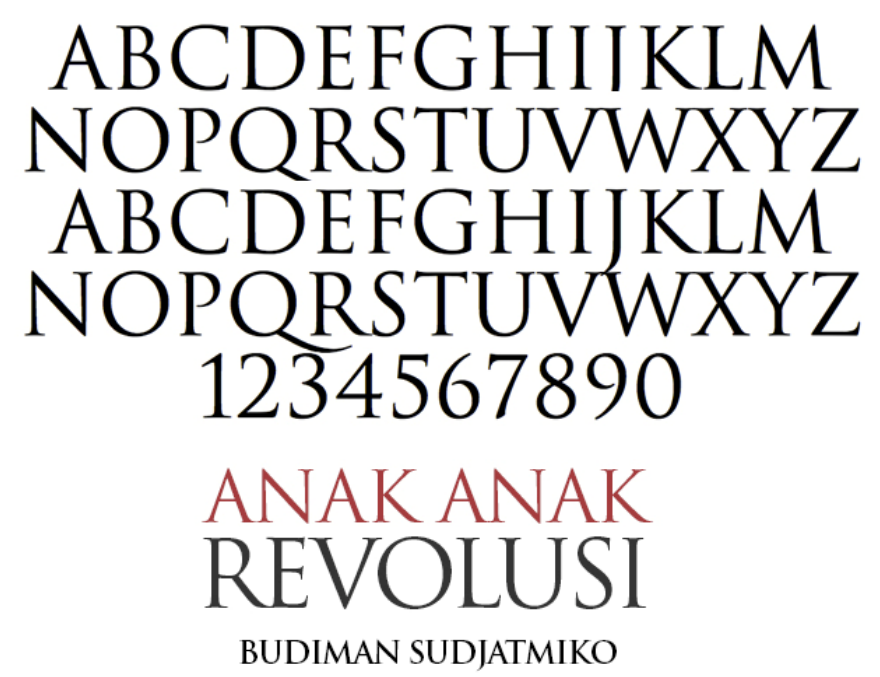

Gambar 2 Jenis Huruf Trajan dan Penerapannya 
Trajan kerap disebut sebagai jenis huruf untuk judul film (movie font) karena teramat seringnya digunakan sebagai jenis huruf pada judul film. Film-film box-office yang telah menjadi pengguna Trajan contohnya film Titanic, Geisha, Last Samurai, I Am Legend, Home of the Brave, film animasi Ice Age hingga serial televisi The West Wing. Biasanya pemanfaatan jenis huruf Trajan di poster film tersebut disertai foto kepala (wajah penuh) pemeran utamanya dalam ukuran besar, tata letak seadanya dan cenderung aman.

Menjadi wajar mengapa Trajan menjadi jenis huruf pilihan banyak orang, karena Trajan adalah jenis huruf yang memiliki bentuk-bentuk kurva yang elegan, stroke yang ramping namun tegas, dan secara keseluruhan memiliki penampilan yang cantik. Lepas dari keindahan Trajan, pemakaian jenis huruf dapat sedemikian masifnya karena Trajan adalah jenis huruf yang turut disertakan di dalam perangkat lunak keluaran Adobe's Creative Suite, hingga hampir pasti seluruh desainer memiliki jenis huruf tersebut (Carpenter, 2011).

Secara mudah, memilih Trajan untuk sampul muka buku Anak-anak Revolusi tidaklah salah, karena seperti yang disebut oleh Friedlander (2011), "You might recognize Trajan, and that's because it's been used for more movie posters than any other font. It works quite well on books, too. This classic font is appropriate for histories, bukus, and historical fiction, among others.” Dan, Anak-anak Revolusi merupakan buku berjenis buku dengan pendekatan sejarah.

Namun, bila kita menelusuri sejarah penciptaan jenis huruf Trajan, maka kita akan menjumpai objek inspirasi yang mengilhami proses kreatifnya. Inspirasi jenis huruf Trajan diperoleh dari prasasti yang terdapat pada tiang (kolom) Trajan yang berangka tahun 114 Masehi. Roma sangat bangga dengan prestasi kekaisaran mereka lewat penaklukan demi penaklukan yang mereka lakukan, untuk itu mereka membangun monumen-monumen arsitektural dengan kolom-kolom berupa prasasti yang bertuliskan perayaan para pemimpin militer serta kemenangan demi kemenangan mereka (Meggs \& Purvis 2006). Dengan sejarah inspirasi yang dimiliki tidak semestinya buku Anak-anak Revolusi menggunakan jenis huruf Trajan karena bertolak belakang dengan kisah yang dibangun. Kisah "Trajan” bicara tentang sebuah perayaan kemenangan para penguasa yang berlumur darah dan air mata, "Trajan" berbicara tentang perayaan bagi para pemimpin militer. Sedang Anak-anak Revolusi bicara tentang memperjuangkan mimpi yang berliku karena harus berhadapan dengan para penguasa. Peran militer yang dirayakan oleh "Trajan” malah menjadi bagian alat represif penguasa yang harus dihadapi oleh para anak-anak revolusi.

\section{Eksekusi Visual}

Pilihan pendekatan closure pada visualisasi sepatu lars amatlah tepat, tanpa harus melakukan ekspose bentuk yang nyata sepatu lars malah justru menimbulkan persepsi represi yang kuat saat melihatnya. Closure sendiri merupakan salah satu prinsip yang mengacu kepada prinsip persepsi Gestalt (Lidwell; Holden; Butler, 2010), prinsip closure ini memungkinkan desainer untuk mereduksi kemungkinan benturan kompleksitas yang mungkin terjadi antara dua objek utama, jejak sepatu lars dan bunga mawar. Desainer tidak perlu mendetail dalam memvisualkan sepatu lars, cukup bentukbentuk abstrak dengan layer dan bermain dalam intensitas warna. Desain tersebut kemudian memberikan ruang bagi mereka yang melihat untuk menyempurnakan atau mengisi bagian-bagian yang hilang dari bentuk tersebut di dalam persepsi pikiran mereka.

Kemungkinan benturan kompleksitas antar elemen juga turut direduksi dengan memanfaatkan prinsip red effect (Lidwell; Holden; Butler, 2010). Warna merah memiliki peran yang signifikan di dalam komunikasi, baik untuk laki-laki dan perempuan. Warna merah pada bunga mawar di sampul muka Anak-anak Revolusi sesungguhnya memberikan daya henti pertama yang sanggup menciptakan interaksi awal saat buku tersebut harus bersanding dengan ratusan buku lain di jejeran rak toko buku. 
Namun, kritik terbesar yang dapat ditujukan pada sampul muka buku ini adalah eksekusi visual yang dipilih yang tidak memiliki karakter. Apa mungkin karena tidak memilih salah satu genre visual? Atau, karena tidak maksimal dalam melakukan eksekusi visual? Banyak pilihan visualisasi yang dapat dilakukan untuk mendapatkan hasil yang optimal, dari ilustrasi berbasis tradisional, digital ataupun fotografi. Pengerjaan mendetil dibutuhkan dalam ekseskusi ini, tujuannya sudah tentu yakni visual yang tak hanya baik, namun juga bagus dan indah.

Beberapa area masih dapat dimaksimalkan untuk mendapatkan detail visualisasi yang tercipta pada jejak sepatu lars yang menginjak bunga, seperti teknik permainan gelap terang dalam membangun bayangan, struktur-struktur bentuk yang merujuk ke bentuk natural (karena jenis/gaya tampilan tersebut sepertinya yang coba diimplementasikan). Tampilan yang ada saat ini tak cukup memperlihatkan beratnya beban yang tercipta akibat beban injakan kaki lewat sepatu lars, yang terlihat adalah bunga mawar yang masih dapat terbilang utuh dan "tertempel" oleh remah tanah hasil tersentuh bagian bawah sepatu lars.

Hanya terlihat menyentuh saja, hingga bunga mawar masih tampak utuh. Hal ini sedikit banyak disebabkan oleh kualitas eksekusi yang belum optimal, termasuk di dalamnya pemilihan digital brush, juga teknik-teknik lukis di media digital yang diterapkan oleh desainer. Hal lain yang masih dapat dicermati adalah tangkai bunga mawar bukankah semestinya memiliki duri? Visual "duri” akan semakin menguatkan cerita yang ingin disampaikan secara visual.

\section{Gaya Visual}

\section{Konstruktivisme}

Agustus 2013 adalah titik awal informasi terkait buku Anak-anak Revolusi dirilis secara informal. Media yang digunakan pun hanyalah Twitter pribadi yang dimiliki Budiman. Kemudian tweets singkat berupa teaser kehadiran buku tersebut hadir sesekali, berperan sebagai media promosi sederhana namun efektif, karena langsung menuju ke para follower.

Semenjak awal informasi berupa teaser tersebut beredar saya segera membayangkan tampilan visual sampul muka Anak-anak Revolusi akan bergaya konstruktivisme, sebuah aliran seni yang berkembang luas di Rusia pada awal abad ke-20 (Meggs \& Purvis 2006), atau pendekatan gaya visual bergaya poster-poster propaganda, didominasi oleh warna merah dan akromatik (hitam, abu-abu, putih). Pendekatan visual tersebut erat dengan gaya visual sosialis, sebuah isme yang menaungi isi buku dan menjadi cara pandang yang dianut oleh Budiman Sudjatmiko.

Gaya desain konstruktivisme erat dengan bentuk geometris yang dipenuhi bentuk statis horisontal dan vertikal serta saling terkait menyatu bagai dalam irama gerak sebuah mesin. Selain itu erat juga dengan pendekatan foto montase, dan tentu saja seperti yang disebutkan di awal, didominasi oleh warna merah dan akromatik. Konstruktivisme menebarkan optimisme, tidak mempercayai ide yang abstrak karena itu mereka menjembatani antara seni dengan ide yang konkrit dan jelas. Dan, tentu saja berusaha menunjukkan keterpihakan mereka terhadap kaum proletar.

Bila mengaitkan semangat konstruktivisme dengan buku Anak-anak Revolusi, setidaknya terdapat tiga hal yang sejalan, yakni optimisme dalam mengejar harapan dan impian, berusaha menjembatani segala yang abstrak dengan segala hal yang lebih konkrit, dan keterpihakan terhadap kaum proletar. Sedang bentuk dan warna yang merepresentasikan konstruktivisme dapat dijadikan elemen-elemen yang membangun gaya desain terkait.

Walau tidak langsung merujuk ke dalam bentuk metafora sepatu lars dan bunga mawar, namun beberapa gaya desain konstruktivisme berikut dapat dijadikan acuan referensi visual dalam pembuatan desain sampul buku Anak-anak Revolusi. 


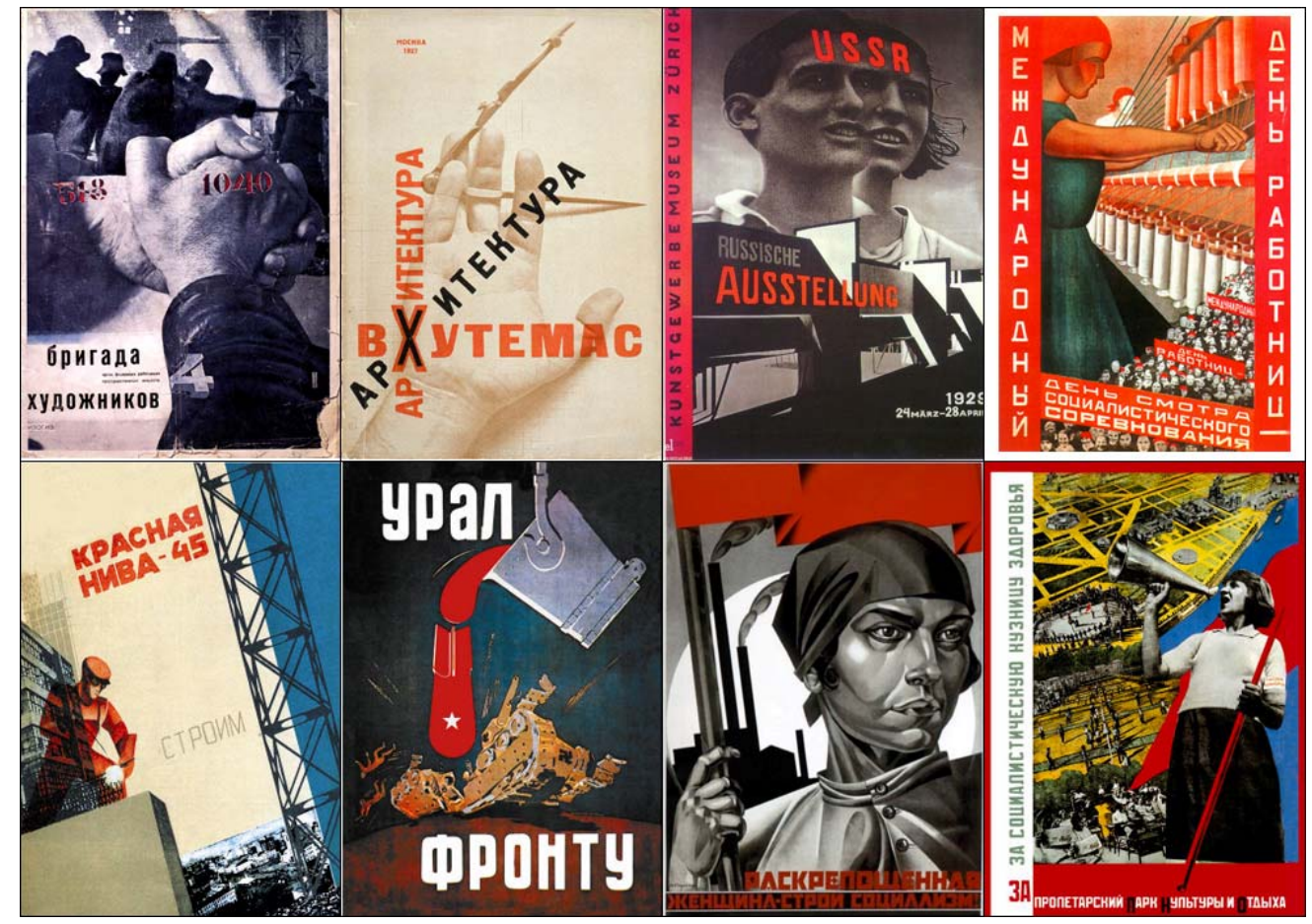

Gambar 3 Cover for Artists' Brigade (El Lissitzky), 'Arkhitektura' cover design (El Lissitzky), Poster for the Russian Exhibition (El Lissitzky), International Women Worker's Day

(Valentina Kulagina), Red Field (Valentina Kulagina), Urals to the Front (Pyotr Karachentsov), You Are Now a Free Woman, Help Build Socialism! (Strakhov Braslavskij),

For the Proletarian Park (Gitsevich)

\section{Cukil Kayu}

Käthe Kollwitz seorang artis kelahiran Jerman, berkarya lewat media gambar, cetak, patung dan poster. Karya figuratif yang lahir dari tangannya sangat kuat dalam emosi, ekspresif dalam memvisualkan kondisi manusia, seperti kondisi menyedihkan dari para pekerja miskin, penderitaan perempuan dan anak-anak, terutama yang disebabkan oleh perang (Meggs \& Purvis 2006).
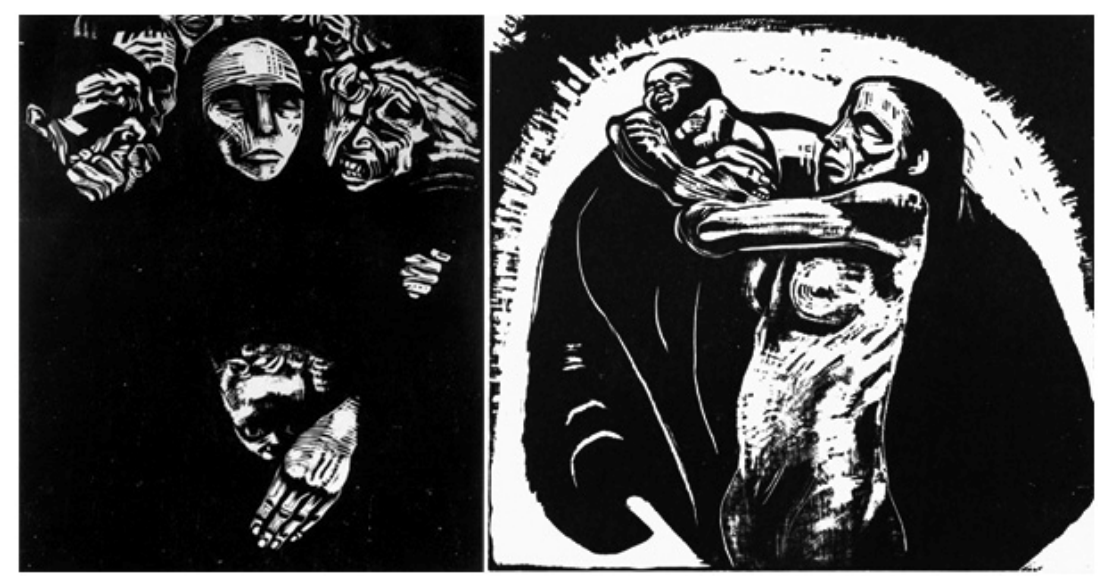

Gambar 4 The People (Das Volk) dan The Sacrifice (Das Opfer) dari koleksi karya berjudul War (Krieg) oleh Käthe Kollwitz 
Dua karya di atas merupakan bagian dari satu paket karya Kollwitz yang berjudul Perang (Krieg), menceritakan kekejaman perang lengkap dengan segenap penderitaan dengan pendekatan figuratif. Karya tersebut menggunakan teknik woodcut (cukilan kayu), sebuah teknik cetak yang menggunakan media cetak papan kayu yang digambar. Gambar tersebut dibentuk dari cukilan. Pada cetakan papan kayu yang digunakan, bagian yang hasilnya akan berwarna akan tetap didiamkan (tidak dicukil), sedang bagian yang tidak ingin berwarna akan dicukil, dipahat ataupun ditatah. Hingga menjadi ruang kosong yang tidak akan terkena cat/pewarna, ruang kosong tersebut nantinya akan menjadi area yang sewarna dengan media cetak yang digunakan. Lalu setelah cetakan tersebut diberi cat/pewarna kemudian ditempelkan (dicetak) ke bidang/media yang ingin dicetak.

Di Indonesia terdapat beberapa aktivis kebudayaan yang menggunakan pendekatan woodcut dalam menghasilkan karya, contohnya Taring Padi. Taring Padi, mengumumkan kehadirannya di kancah Politik-Budaya Yogyakarta. Taring Padi mendeklarasikan Mukadimahnya dan mengumumkan Lima Iblis Budaya di kantor LBH Yogyakarta pada 21 Desember 1998 (http://taringpadi.com).Taring Padi memiliki filosofi: seni bukan barang elite yang hanya bisa dinikmati di ruang-ruang galeri. Seni adalah karya yang membumi dan melibatkan rakyat (Majalah Tempo, September 2013). Suara dari ketertindasan adalah tema yang kerap diusung oleh Taring Padi, mereka menggunakan media baliho, poster cukil kayu, dan mural.

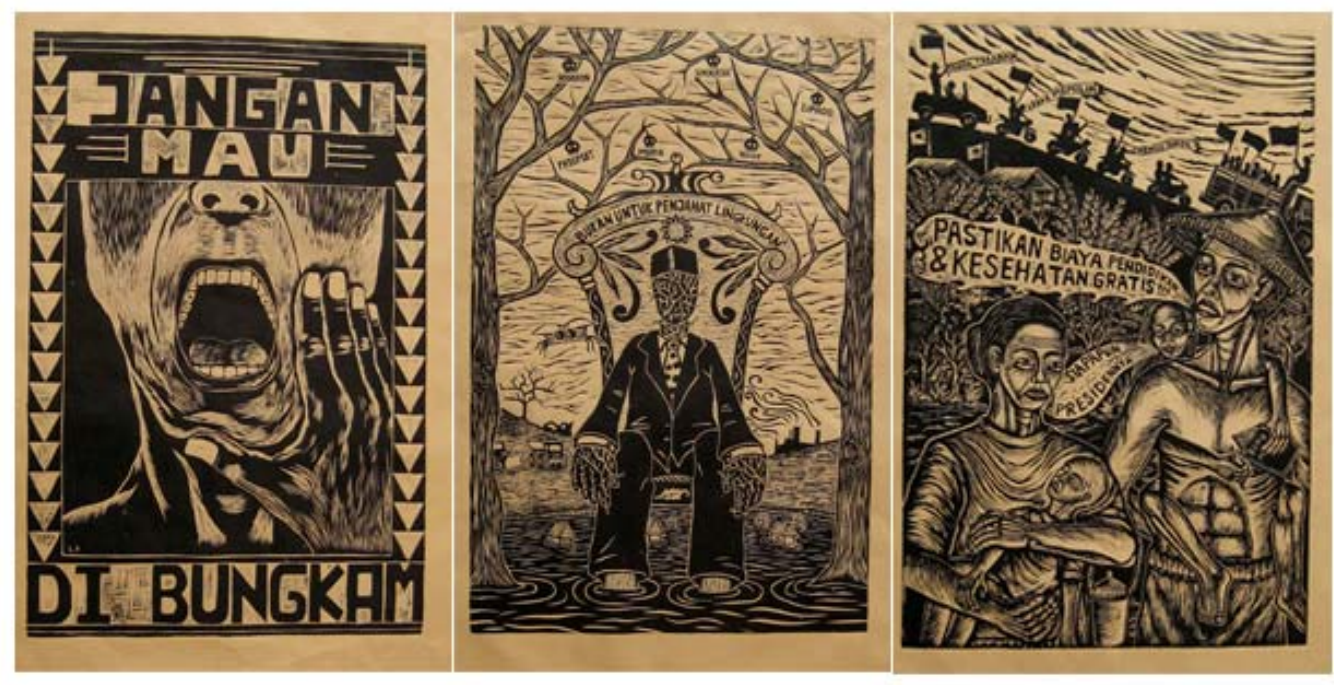

Gambar 5 Contoh karya dari Taring Padi

(Sumber gambar http://taringpadi.com)

Hasil karya Kollwitz dan Taring Padi yang menggunakan teknik cukil kayu identik dengan kaum proletar, kaum bawah, kaum yang terpinggirkan, juga lekat dengan kaum pekerja. Teknik cukil kayu dianggap sebagai representasi dari kerja tangan para buruh/kuli, juga dianggap sebagai bentuk kesederhanaan yangmerepresentasikan proses cetak dengan tahap dan proses yang tidak rumit, serta relatif sangat murah di dalam biaya produksi karya. Representasi tersebut akhirnya menjadi pilihan yang diambil oleh para seniman-seniman yang menyuarakan ketertindasan.

Pilihan visualisasi desain dengan menggunakan teknik cukil ini semestinya bisa menjadi alternatif gaya visual yang diusung oleh desain sampul muka buku Anak-anak Revolusi, karena semangat yang menaungi buku tersebut erat dengan representasi yang diusung oleh teknik cukil yang ada, yakni bicara tentang kaum proletar, bicara tentang kesederhanaan, serta perlawanan atas ketertindasan. 


\section{Selebaran Fotokopi dan Cetak Stensil Murah}

Teringat akan satu momen waktu di masa lalu, sekitar tahun 1996-1998, saat-saat membaca lembaran demi lembaran selebaran yang saat itu terkategorikan sebagai selebaran subversif. Lembaran itu sangat sederhana, tercetak lewat mesin fotokopi di kertas putih yang tak tebal. Kerap kali lembaran yang didapat itu adalah hasil fotokopi yang kesekian, hingga huruf-huruf yang terkopi di sana menjadi telah memudar, tak jelas keterbacaannya. Kertasnya pun kadang telah lusuh dan kusam. Kadang yang didapat adalah cetakan stensilan yang tintanya mem-blaur di sana sini, tercetak di atas kertas buram ataupun hvs kusam.

Saat itu, hanya untuk memegang selembaran itu dibutuhkan keberanian, membacanya harus sambil sembunyi-sembunyi, tak ada yang berani membacanya di tempat umum. Bila ada yang ingin menggandakan biasanya diberikan wejangan panjang berisi pesan penuh kehati-hatian. Solidaritas Mahasiswa Indonesia untuk Demokrasi (SMID) adalah gerakan mahasiswa untuk memperjuangkan demokrasi di Indonesia, organisasi ini merupakan onderbouw dari Partai Rakyat Demokratik (PRD) Budiman Sudjatmiko. SMID merupakan salah satu organisasi yang paling gencar menyebarkan selebaran tersebut. Selebaran tersebut biasanya berisi berita aksi mahasiswa ataupun buruh, isu-isu terkait demokrasi, politik dan sosial-ekonomi yang semakin memburuk.

Majalah Tempo pada Mei 2013 merilis edisi khusus dengan memberikan bonus berupa buku kecil yang berisi kumpulan puisi Wiji Thukul. Wiji Thukul adalah seorang penyair dan aktivis yang masuk di dalam daftar orang hilang semenjak tahun 2000. Buku kecil tersebut sangatlah sederhana, bersampul coklat dengan judul tercetak merah dan hitam. Di sudut kanan bawah tervisualkan sepatu lars serdadu dengan ujung sepatu berbentuk mulut buaya, lengkap dengan deretan gigi tajamnya. Buku tipis itu terjilid hanya dengan staples, sedang bagian dalamnya tercetak offset satu warna, berusaha menghadirkan nuansa kusam dan pudar fotokopi. Buku sederhana itu berhasil menghadirkan memori atas selebaran propaganda masa lalu.

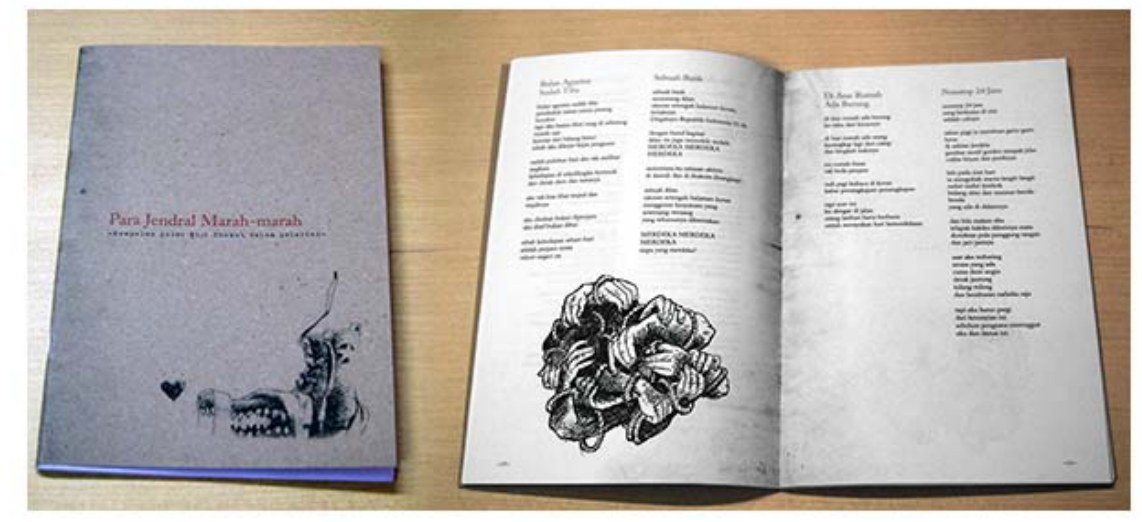

Gambar 6 Kumpulan Puisi Wiji Thukul dalam pelarian, “Para Jendral Marah-marah. Edisi khusus Majalah Tempo, Mei 2013

Dalam desain, pendekatan seperti di atas kerap disebut dengan rekonstruksi (Lupton, 2011). Cara yang dapat ditempuh untuk melakukan desain rekonstruksi tersebut yakni dengan melakukan pengumpulan artefak visual yang terkait, melakukan analisa dan replika, observasi kemudian terakhir eksekusi visual. Buku Anak-anak Revolusi dapat menggunakan pendekatan serupa untuk menghadirkan visual masa lalu sebagai satu kesatuan karya, bukan berarti dalam bentuk yang serupa, namun yang dapat serupa adalah proses pengembangan desainnya lewat langkah kreatif yang sama. 


\section{SIMPULAN}

Sampul muka sebuah buku memiliki peran yang sangat penting di dalam sebuah produksi buku. Sampul muka buku harus mampu merepresentasikan keseluruhan isi buku, memberikan gambaran utuh atas naskah yang terdapat di dalamnya hingga dapat menjawab ekspektasi dari pembacanya. Selain itu juga berperan sebagai identifikasi yang unik, bukan hanya sebagai pengingat namun juga karena harus bersaing pada saat terpajang di toko buku, bersaing meraih perhatian dengan puluhan bahkan ratusan buku lainnya. Buku Anak-anak Revolusi karya Budiman Sudjatmiko memiliki isi naskah yang hebat, memiliki pilihan metafora untuk sampul muka buku yang tepat, namun saat eksekusi visual masih ditemui kekurangan di sana-sini yang semestinya dapat dioptimalkan agar buku Anak-anak Revolusi dapat hadir lebih utuh, lengkap di segala aspek dan lini untuk menjadi sebuah buku yang sempurna.

\section{DAFTAR PUSTAKA}

Carpenter, M. (2011). 10 Iconic Fonts and Why You Should Never Use Them, Diakses 28 November 2013, dari http://www.webdesignerdepot.com/2011/02/10-iconic-fonts-and-why-you-shouldnever-use-them

Friedlander, J. (2012). Book Cover Design and the Problem of Symbolism, Diakses 3 Desember 2013 dari http://www.thebookdesigner.com/2012/01/book-cover-design-and-the-problem-ofsymbolism

Friedlander, J. (2011). 5 Great Fonts for Book Covers, Diakses 28 November 2013, dari http://www.thebookdesigner.com/2011/08/5-great-fonts-for-book-covers/

IMDB.com. Missing (1982) Diakses 29 November 2013, dari http://www.imdb.com/title/tt0084335/

Lidwell, W., Holden, K., Butler, J. (2010). Universal Principles of design: a cross-disciplinary reference. Massachusetts: Rockport Publishers, Inc.

Lupton, E. (2011).Graphic Design Thinking: Beyond Brainstorming. New York: Pricenton Architectural Press.

Lupton, E. (2004). Thinking with Type. Graphic Design the New Basic. New York: Pricenton Architectural Press.

Taring Padi (2010) Tentang Taring Padi. Diakses 29 November 2013, dari http://taringpadi.com/about/?lang=in/

Meggs, P. B., Alston W. P. (2006). Meggs' History of Graphic Design (4th ed.). New Jersey: John Wiley \& Sons, Inc. 


\section{Lampiran}

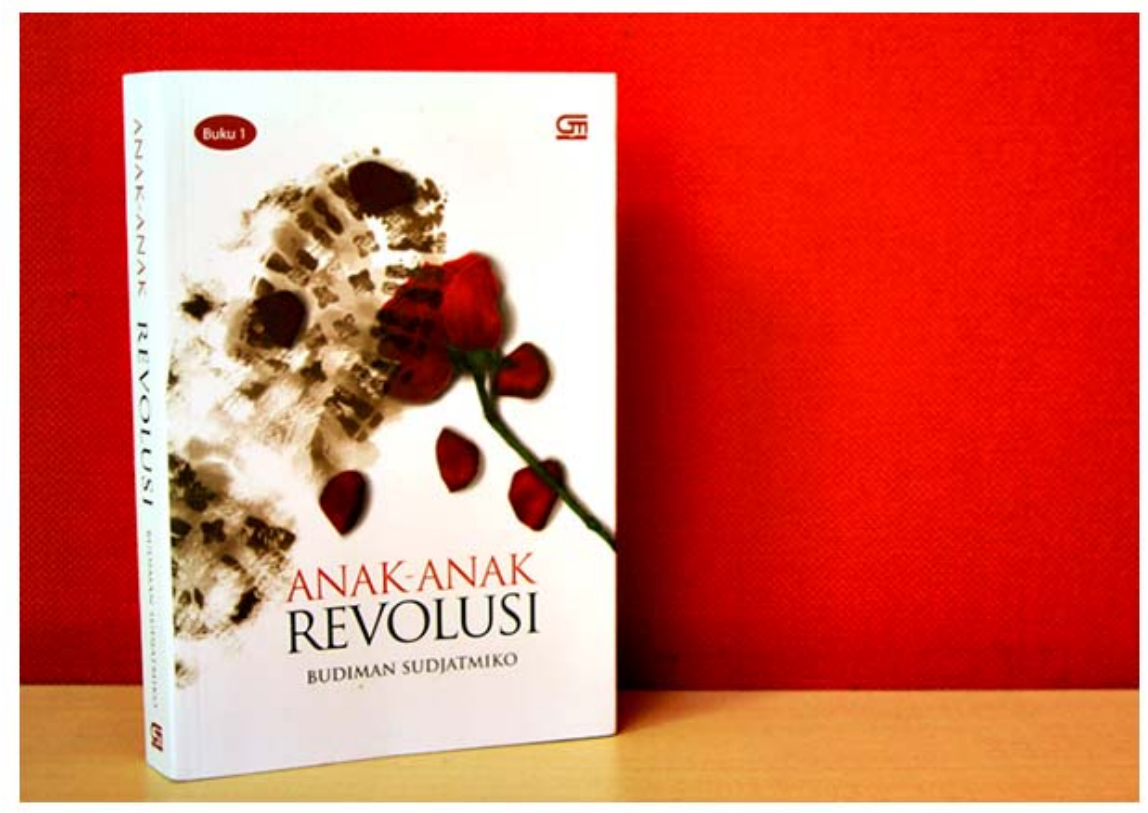

“Tak tertinggal dua sahabatku yang lain, Vande Leonardo maupun Billy Franata, yang bisa menerjemahkan bagaimana fisik buku ini harus ditampilkan. Merekalah yang menghadirkan setangkai mawar merah yang terinjak sepatu lars kekuasaan (ah... betapa mencekamnya saat aku menatap rancangan sampul muka buku ini, sampai-sampai aku harus menyiulkan theme song dari film karya Costa Gavras "Missing”, yang mengisahkan anak-anak revolusi yang hilang pada tahun 1973 di sebuah negeri yang jauh, Chile.”

(Kata Pengantar Budiman Sudjatmiko di buku Anak-anak Revolusi) 